\title{
Prevalence and Determinants of Active and Passive Cigarette Smoking among undergraduate students at Hawassa University, Hawassa, Ethiopia
}

\author{
Andargachew Kassa ${ }^{1^{*}}$ and Serawit Deyno ${ }^{2}$ \\ ${ }^{1}$ School of Nursing and Midwifery, College of Medicine and Health Sciences, Hawassa University, Ethiopia \\ ${ }^{2}$ Pharmacology Unit, School of Medicine, College of Medicine and Health Sciences, Hawassa University, Ethiopia \\ *Corresponding author: Andargachew Kassa, School of Nursing and Midwifery, College of Medicine and Health Sciences, Hawassa University, Ethiopia, Tel: $+49-551$ \\ 39-221; E-mail: andkassa@hu.edu.et
}

Rec Date: May 11, 2014, Acc Date: Jun 10, 2014, Pub Date: Jun 12, 2014

Copyright: (c) 2014 Kassa et al. This is an open-access article distributed under the terms of the Creative Commons Attribution License, which permits unrestricted use, distribution, and reproduction in any medium, provided the original author and source are credited.

\begin{abstract}
Background: Smoking, one of the most preventable causes of death, kills approximately 6 million people worldwide. The aim of this study is to determine the prevalence of smoking and its determinants among undergraduate students at Hawassa University.

Methods: Institution-based cross-sectional study was conducted using structured self-administered questionnaires among 586 undergraduate students at Hawassa University. Using multi-stage sampling technique. Bivariate and multivariate logistic regression analyses were performed to determine determinants of tobacco use.

Results: Among 586 students participated in the study $14.8 \%$ have ever cigarette used in their life time and $7.5 \%$ used tobacco in the previous 30 days. The mean age of initiating smoking cigarette was mean (SD) (15.43 \pm 2.92 years). The vast majority $(69 \%)$ of undergraduate students at Hawassa University reported that they were exposed to environmental cigarette smoke. Among those reported to have cigarette smoke exposure $17 \%(n=397)$ are exposed on daily. Khat chewing and alcohol use were positive predictors whereas living with brothers and/or sisters during student's school age were a negative predictor of smoking cigarette.

Conclusion and recommendation: Active and passive cigarette smoking are prevalent among Hawassa university undergraduate students. Ever chewing khat and ever drinking alcohol were independent predictors of smoking cigarette. We recommend a concerted effort of integrated cigarette smoking and substance use prevention campaigns in the university students.
\end{abstract}

Keywords: Tobacco; Passive cigarette smoke; University students

\section{Introduction}

Smoking is one of the greatest problems in public health worldwide and one of the most preventable causes of death [1]. Tobacco kills approximately 6 million people and causes more than half a trillion dollars of economic damage each year worldwide. Although tobacco use continues to be the leading global cause of preventable death, there are proven, cost-effective means to combat this deadly epidemic [2]. Unless urgent action is taken, the annual death toll could rise to more than eight million by 2030 [2].

Cigarette smoking has been described as a "gate way" substance towards illicit drug use among adolescents [3]. The onset of tobacco use occurs primarily in early adolescence, a developmental stage that is far removed by several decades from the death and disability that are associated with smoking in adulthood [4]. Therefore, the fact that many adult smokers initiated their smoking habit as adolescents makes adolescence smoking a significant public health problem [5].

Passive smoking is defined as involuntary exposure to a diluted combination of cigarette side stream smoke (gas and particle phases evolved from the smouldering end of a cigarette) and mainstream smoke (mixture inhaled by the smoker and exhaled after lung filtration) [6]. Sidestream smoke is believed to be the primary source of cigarette smoke exposure of nonsmokers [6,7]. Secondhand smoke consists of a mixture of gases and particles including smoke from burning cigarettes, cigars, pipe tobacco, and exhaled mainstream smoke [2]. Evidence suggests that exposure to secondhand smoke also can result in adverse health effects, including heart disease in nonsmoking adults. Since 1964, 2.5 million nonsmokers have died from exposure to secondhand smoke $[2,8]$.

Available few studies indicate that psychoactive substance use among Ethiopian adolescents is considerably rising [9,10]. WHO report indicates that $51-80 \%$ youth (13-15 years old) have noticed tobacco advertising on billboards during the last 30 days before the survey [2]. The Ethiopian Demographic and Health Survey (EDHS) 2005 report, among men in range of 15-49 years age in Ethiopia, 9\% of them smoke cigarettes. Even though there is no complete data on the prevalence of smoking among women, EDHS reported that less than $2 \%$ of women in Ethiopia smoke cigarettes [11]. Although hard drug abuse is low in Ethiopia, the use of locally growing psycho-stimulants such as tobacco, khat and cannabis is growing [12].

Smoking prevalence in Ethiopia is increasing, particularly among the youth. A study of smoking prevalence in the early 1980s showed that smoking prevalence among 18-20 years olds was $38 \%$ for males and $3.4 \%$ among females [13]. A study conducted in 1983 found that smoking rates were $28 \%$ among medical students: with prevalence increasing by age and the majority of smokers starting smoking 
between the ages of 16 to 18 years [13]. Another study, "drug use among high school students in Addis Ababa and Butajira", showed that cigarette smoking is more prevalent in private schools (48\%) than in governmental schools (5\% and 6\% in Addis Ababa and Butajira respectively)[10].

Very few studies indicate cigarette smoking have become common practices among high school students in Ethiopia [10,14] and college/ university students in Ethiopia [15], only very few studies have assessed their magnitude and the associated factor [9]. These very few studies are insufficient to generalize the current in smoking and more studies are required to design interventional strategies. In addition, to the best of authors' knowledge, there is no study conducted in Ethiopia to determine the prevalence of exposure to second-hand smoke. Therefore the objective of this study was to determine the prevalence of both passive and active smoking and its determinants among undergraduate students at Hawassa University.

\section{Methods}

Study data was collected from June 1 to July 30, 2011 among Hawassa University students located in Hawassa town, Sidama Zone, Southern Ethiopia. Hawassa is located $275 \mathrm{~km}$ from Addis Ababa, the capital of Ethiopia. A total of 15,104 undergraduate students \& 58 academic departments were available in the university during the study period.

Institution-based cross-sectional quantitative study design was used. The study population was all regular undergraduate students attending four colleges found in the university; namely: main campus, referral campus, agricultural and Wondogenet campuses. Students absent from the class during the study time were not included in the study population.

The sample size was calculated using single population proportion formula taking assumption of prevalence of substances use $22.0 \%$, from "undergraduate medical students study of Addis Ababa University in Ethiopia"[16]. Using 5\% margin of error and 95\% confidence level, $12 \%$ non response rate, and design effect of two the sample size was calculated to be 590 .

Multi-stage sampling technique was used. During the first stage, by using simple random sampling technique, twenty five (25) departments were selected from a total of 58 departments. In the second stage, departments in each field of study were further stratified by their years of study and sex, assuming that their duration of stay in the campus and sex would affect psychoactive substance (PAS) use among the students. The total sample size was distributed proportionally to the selected departments based on total number of students in each year of study with their sex distribution. Finally, individual students fulfilling the inclusion criterion were randomly selected to be participants of the study.
We used the following operational definitions. Life time prevalence of Active Cigarette Smoking was defined as percentage of students who had ever tried smoking cigarettes during his/her past life time. Current prevalence of active cigarette smoking was defined as percentage of student who had smoked cigarettes on one or more days in the preceding month ( 30 days) of the survey. Current prevalence of passive smoking was defined as the percentage of students exposed to smoke during the last 30 days.

Active cigarette smoking and passive cigarette smoking were dependent variables. The independent variables include: Sociodemographic characteristics (age, sex, marital status and ethnicity), years of study, religion, and living condition during school age, family member substances use history, coming from orphanage center, mother and father's educational status and knowledge on the health risks of cigarette use.

A pre tested structured interview questionnaire, The GYTS (Global Tobacco Surveillance System questionnaire) was customized to fit the local context and objectives of the study according to the studies reviewed. Pre-test was done on $10 \%$ of the subjects at Dilla University.

The collected data were cleaned, coded, entered into software and analyzed using SPSS computer software package version 20 . Summary statistics of socio-demographic variables were presented using frequency tables and graphs. Bivariate analysis was done and variables with p-value less than 0.05 were included in the multiple logistic regression analysis. Odds ratio and $95 \%$ confidence intervals were also computed.

The study ethical clearance was obtained from institution research review board of college of medicine and health science of Hawassa University. The aim and the importance of the study were explained and written consent was obtained from each participant. Moreover, confidentiality of the information was assured by using anonymous questionnaires and by keeping the data in a secured place.

\section{Results}

\section{Socio-demographic characteristics of the respondents}

A total of 586 undergraduate students were involved in this study out of $590 \%$ planed study population which has the response rate of (99.3\%). Male comprises of 419 (81.7\%) of the study population. 468 (69.2\%) of the study population were in the age group of $20-24$ and the respondents mean (SD) age of the study participants were $20.7( \pm 1.49)$ years. The majority were Orthodox Christian followers (59.71\%). See Table 1: A table which was also used on authors' research report published elsewhere[17].

\section{Age of initiating cigarette smoking}

The mean age of initiating smoking cigarette was mean (SD) 16.62 \pm 2.92 years. 
Citation: Kassa A, Deyno S (2014) Prevalence and Determinants of Active and Passive Cigarette Smoking among undergraduate student at Hawassa University, Hawassa, Ethiopia. J Trop Dis 2: 145. doi:10.4172/2329-891X.1000145

\begin{tabular}{|c|c|c|c|}
\hline \multirow[t]{2}{*}{ Characteristics } & \multicolumn{2}{|l|}{ Sex } & \multirow[t]{2}{*}{ Total $\mathbf{n}(\%)$} \\
\hline & Male n (\%) & Female n (\%) & \\
\hline \multicolumn{4}{|l|}{ Age group( years) } \\
\hline $15-19$ & $72(12 \%)$ & $34(5.8 \%)$ & $106(18.02 \%)$ \\
\hline $20-24$ & $397(67.9 \%)$ & $71(12.07 \%)$ & $468(69.2 \%)$ \\
\hline $25-30$ & $10(1.71 \%)$ & $2(0.34 \%)$ & $12(2.05 \%)$ \\
\hline Total & $419(81.7 \%)$ & $107(18.3 \%)$ & $586(100 \%)$ \\
\hline \multicolumn{4}{|l|}{ Religion } \\
\hline Orthodox Christian & $285(48.62 \%)$ & $65(11.08 \%)$ & $350(59.71 \%)$ \\
\hline Protestant Christian & $127(21.66 \%)$ & $29(4.94 \%)$ & $156(26.61 \%)$ \\
\hline Muslim & $53(9.04 \%)$ & $9(1.53 \%)$ & $62(10.58 \%)$ \\
\hline Others & $14(2.38 \%)$ & $4(0.7 \%)$ & $18(3.07 \%)$ \\
\hline Total & $479(81.71 \%)$ & $107(18.25 \%)$ & $586(100 \%)$ \\
\hline \multicolumn{4}{|l|}{ Year of Education } \\
\hline Year I & 195(33.15\%) & $48(8.16 \%)$ & $243(41.31 \%)$ \\
\hline Year II & $115(19.60 \%)$ & $30(5.1 \%)$ & $145(24.70 \%)$ \\
\hline Year III & $148(25.16 \%)$ & $23(3.91 \%)$ & $171(29.07 \%)$ \\
\hline Year IV & $13(2.21 \%)$ & $3(0.51 \%)$ & $16(2.72 \%)$ \\
\hline Year V & $5(0.90 \%)$ & $2(0.34 \%)$ & $7(1.19 \%)$ \\
\hline Year V I/ Internship & $3(0.51 \%)$ & $1(0.17 \%)$ & $4(0.68 \%)$ \\
\hline Total & $479(81.43 \%)$ & $107(18.19 \%)$ & $586(100)$ \\
\hline \multicolumn{4}{|c|}{ Mother's educational level } \\
\hline Illiterate & $192(32.64 \%)$ & $14(2.38 \%)$ & $206(35.02 \%)$ \\
\hline Elementary to Grade 12 & $202(34.34 \%)$ & $54(9.18 \%)$ & $256(43.52 \%)$ \\
\hline College or University & $69(11.73 \%)$ & $38(6.46 \%)$ & $107(18.19 \% 0$ \\
\hline Do not Know & $16(2.72 \%)$ & $1(0.17 \%)$ & $17(2.89 \%)$ \\
\hline Total & $479(81.43 \%)$ & $107(18.19 \%)$ & $586(100 \%)$ \\
\hline \multicolumn{4}{|l|}{ Father's educational level } \\
\hline Illiterate & $118(20.6 \%)$ & $8(1.36 \%)$ & $126(\%)$ \\
\hline Elementary to Grade 12 & $228(38.76 \%)$ & $44(7.48 \%)$ & $272(\%)$ \\
\hline College or University & $114(19.38 \%)$ & $52(8.84 \%)$ & $166(\%)$ \\
\hline Do not Know & $19(3.23 \%)$ & $3(0.51 \%)$ & $22(\%)$ \\
\hline Total & $479(81.43 \%)$ & $107(18.19 \%)$ & $586(100 \%)$ \\
\hline
\end{tabular}

Table 1: Socio-demographic characteristics of Hawassa University students by sex, (n=586) June/July 2011 
Citation: Kassa A, Deyno S (2014) Prevalence and Determinants of Active and Passive Cigarette Smoking among undergraduate students at Hawassa University, Hawassa, Ethiopia. J Trop Dis 2: 145. doi:10.4172/2329-891X.1000145

Page 4 of 6

\begin{tabular}{|c|c|c|c|c|c|c|}
\hline \multirow[t]{2}{*}{ Type of Substances abused } & \multicolumn{6}{|c|}{ Total $(n=586)$} \\
\hline & No & $\%$ & Male & & Female & \\
\hline & $\mathrm{n}=586$ & & No & $\%$ & No & $\%$ \\
\hline Smoke cigarette Ever & 87 & $14.8 \%$ & 76 & 87.35 & 11 & 12.6 \\
\hline Smoked cigarette in the last 12 Month & 70 & $11.9 \%$ & 63 & 89.9 & 7 & 9.9 \\
\hline Smoked Cigarette in the Past 30 Days & 44 & $7.5 \%$ & 37 & 84.09 & 7 & 15.9 \\
\hline Ever Used Shisha & 54 & $9.2 \%$ & 42 & 77.77 & 12 & 22.22 \\
\hline
\end{tabular}

Table 2: The Life Time, last 12 Month \& Current Prevalence of Cigarette Use among Hawassa University Undergraduate students ( $\mathrm{n}=586)$ June/ July 2011

\section{Correlates of cigarette use}

The multivariate logistic regression analysis depicted that those students who ever chewed khat had the odds of cigarette smoking which is 19 times higher from those who ever never used khat (AOR= $19.153 ; 95 \% \mathrm{CI}=8.67-42.310)$. Similarly those who ever used alcohol had the odds of about five times higher chance of smoking than students who never ever used $(\mathrm{AOR}=4.677 ; 95 \% \mathrm{CI}=1.831-11.948)$. The finding of this research also showed that students who lived with their brothers and sisters, during their school age, showed that lesser odds of smoking cigarette than those who lived alone $(\mathrm{AOR}=0.433$; $95 \% \mathrm{CI}=0.224-0.838$ ) (Table 3).

\begin{tabular}{|c|c|c|c|c|}
\hline \multirow[t]{2}{*}{ Variables } & \multicolumn{2}{|c|}{ Cigarette Smoking } & \multirow{2}{*}{$\operatorname{COR}(95 \% \mathrm{Cl})$} & \multirow{2}{*}{$\mathrm{AOR}(95 \% \mathrm{Cl})$} \\
\hline & Yes & No & & \\
\hline \multicolumn{5}{|l|}{ Year of Education } \\
\hline Year II \& Above & 50 & 293 & $1.903(1.101-3.288)$ & \\
\hline Year I & 20 & 223 & $1^{*}$ & \\
\hline $\begin{array}{l}\text { Family substance use history } \\
\text { Yes }\end{array}$ & 18 & 79 & $1.915(1.064-3.444)$ & \\
\hline No & 52 & 437 & $1^{*}$ & \\
\hline $\begin{array}{l}\text { Living with brother/s and/or sister/s } \\
\text { during school age } \\
\text { Yes } \\
\text { No }\end{array}$ & $\begin{array}{l}35 \\
35\end{array}$ & $\begin{array}{l}345 \\
169\end{array}$ & $\begin{array}{l}0.487(0.294-0.806) \\
1^{*}\end{array}$ & $0.433(0.22-0.84)$ \\
\hline \multicolumn{5}{|l|}{ Fathers Education } \\
\hline High school \& Above & 72 & 214 & $2.368(1.397-4.015)$ & \\
\hline Elementary \& Below & 47 & 253 & $1^{*}$ & \\
\hline \multicolumn{5}{|l|}{ Mothers Education } \\
\hline High school \& Above & 34 & 171 & $1.905(1.152-3.152)$ & \\
\hline Elementary \& below & 36 & 345 & $1^{*}$ & \\
\hline \multirow{2}{*}{$\begin{array}{l}\text { Pear Influence } \\
\text { Yes } \\
\text { No }\end{array}$} & 20 & 70 & $2.549(1.432-4.536)$ & \\
\hline & 50 & 446 & $1^{*}$ & \\
\hline \multirow{2}{*}{$\begin{array}{l}\text { Ever chewed Khat } \\
\text { Yes } \\
\text { No }\end{array}$} & 60 & 81 & $32.22(15.84-65.56)$ & 19.15(8.67 - 42.31) \\
\hline & 10 & 435 & $1^{*}$ & \\
\hline \multirow{2}{*}{$\begin{array}{l}\text { Ever used alcohol } \\
\text { Yes } \\
\text { No } \\
\end{array}$} & 64 & 220 & $12.24(5.517-27.16)$ & $4.677(1.83-11.95)$ \\
\hline & 6 & 295 & $1^{*}$ & \\
\hline
\end{tabular}

Table 3: Bivariate and multivariate logistic regression analysis showing Socio-demographic and behavioral correlates of Cigarette use within the last 12 months among Hawassa University undergraduate students, June/July 2011 


\section{Environmental cigarette smoke exposure (Passive Smoking)}

Overall, 69\% of undergraduate students at Hawassa University reported that they were exposed to environmental cigarette smoke within the campuses. Students reported that they are exposed to passive smoking almost in all areas within the campuses such as; University compound, dormitory, toilet/latrine, lounge, cafe \& class rooms. See Figures-3 and 4). Among those reported to have cigarette smoke exposure $17 \%(n=397)$ were exposed daily.

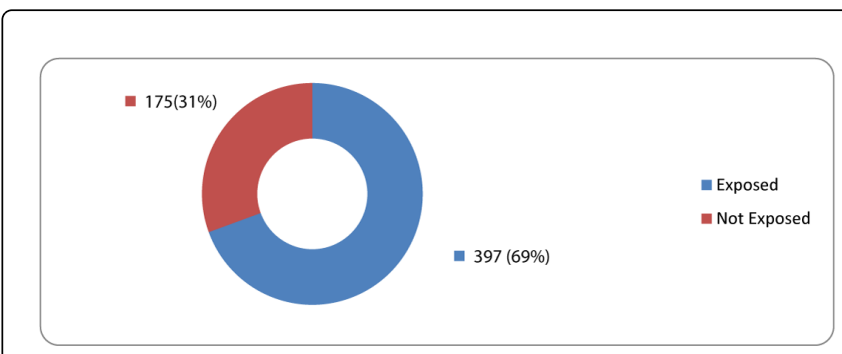

Figure 1: Exposure Status of Undergraduate Hawassa University Students for Cigarette Smoke $(\mathrm{n}=572)$

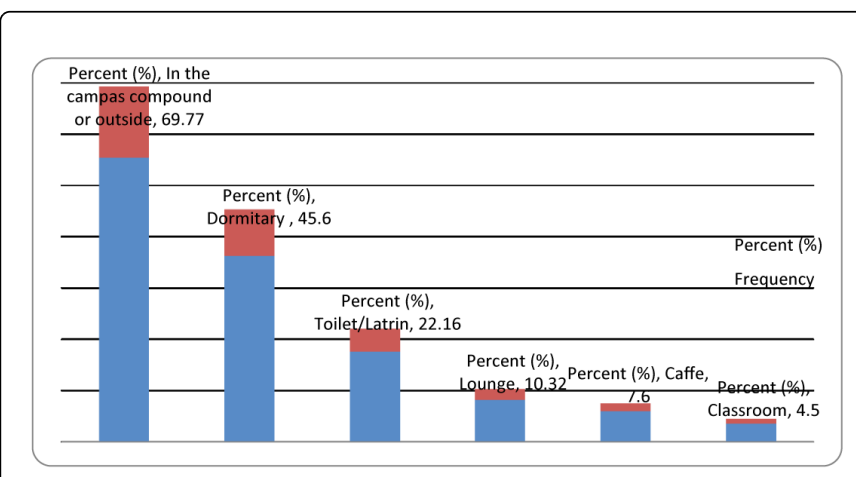

Figure 2: Places of Exposure to Cigarette Smoke to Undergraduate Hawassa University Students $(n=397)$

\section{Discussion}

This study revealed that $14.8 \%$ of the students had ever smoked cigarette, $11.9 \%$ had smoked in the last 12 months and $7.5 \%$ current smokers (defined as smoking in the last 30 days). The prevalence of current smoking in this study is almost similar to the study conducted in Axum university students (9.3\%) [18] and much lesser than a study conducted on Addis Ababa university medical students (1.8\%) [16]. The prevalence of ever smoking in this study is much higher than studies conducted on Addis Ababa university and lower than studies conducted on Axum university [16,18]. Current smoking status in this study is similar to national average $7.2 \%$ [19]. The prevalence of ever smoking in this a little greater than the value reported among school adolescents in eastern Ethiopia (12.2\%) [20]. The eastern part of Ethiopia is an area of high cigarette smoking prevalence [21]. This may be an indicative of cigarette smoking as norm that is gained through cultural acquisition.

The current prevalence rate of cigarette smoking among university instructors in Ethiopia were found to be $13.3 \%$ which is much higher than this study [22].
This is discouraging news, because the students may learn this bad habit from their instructors. Therefore, interventional studies targeting prevention and cessation of smoking cigarette in students has to be included. Proportion of current smokers is almost half that of prevalence of ever smokers. This can indicate that there is a good number of study participants quitting or trying to quite cigarette smoking. It can be anticipated cessation attempts can work effectively.

Vast majority about $69 \%$ of undergraduate Hawassa University students reported that they are being exposed to second hand cigarette smoke within Hawassa University Campuses. These exposure rates is higher than a report in Ethiopian high school students in which almost $20 \%$ of students were exposed, over $40 \%$ are exposed to smoke in public places, and $10 \%$ have parents who smoke [23].

Our finding agrees with the report of united states of America in which an estimated 88 million nonsmokers in the United States were exposed to secondhand smoke in 2007-2008 [24]. The second hand smoking has devastating consequences as it had caused nearly 34,000 heart disease deaths annually (during 2005-2009) among adult nonsmokers in the United States [8].

Most of the second hand smoking exposures in the university students occur in the campus compound, dormitory university compound, dormitory, toilet/latrine, lounge, and cafe \& class rooms. Most of the exposure is evidently from indoor concentrated tobacco smokes. House of Peoples' Representatives pass a new tobacco control proclamation prohibiting smoking in public places and putting enormous taxes on and increasing the price of cigarettes. The proclamation also enforces for the cigarette packages to have a notifying message as to the health dangers of tobacco. Moreover, the proclamation forbids advertising and promoting tobacco products on the media. Yet these rules and bans are not working as a greater segment of the students in university are exposed to second hand smoke.

Ever chewing khat and ever drinking alcohol were independent predictors of smoking cigarette in last 12 months among the study subjects while living with brother/s and/or sister/s during school age decreases the odds of involving in smoking cigarette in the last 12 months. Familial relationships including care and family related activities may protect from involving in tobacco use [25]. Having friends who smoked cigarettes had had been reported to increase the odds of smoking compared to non-smoking friends $[10,18,26]$.

Increasing the unit price for tobacco products and conducting mass media campaigns in combination with other interventions (such as school-based education and community education) had been recommended to prevent young people from initiating smoking. School-based education and community education during high school life is best method to prevent adolescents' from initiating smoking cigarette.

Limitation of the study: our study is conducted in one university students only and may not necessarily be generalizable to all university students in Ethiopia. There may also be recall biases as students may not recall whether or not they smoked within the past 30 days prior to the day of the study and subjective recall biases. Our study however has many strengths for example the students of the university come from all over the country and it can be a good representative of national university students. 
Citation: Kassa A, Deyno S (2014) Prevalence and Determinants of Active and Passive Cigarette Smoking among undergraduate students at Hawassa University, Hawassa, Ethiopia. J Trop Dis 2: 145. doi:10.4172/2329-891X.1000145

Page 6 of 6

\section{Conclusion}

This study revealed that active and passive smoking cigarette became an urgent problem among undergraduate university students. Ever chewing and drinking are independent predictors of smoking cigarette.

Recommendation: we recommend a concerted effort of integrated cigarette smoking and substance use prevention campaigns in university students to halt further advancement of the problem. The campaigns should include awareness creation and bringing behavioral changes.

\section{Conflict of interests}

We declare that we have no competing interests.

\section{Authors' contribution}

Andargachew Kassa conceived the research, developed the proposal, and facilitated data collection.

Andargachew Kassa and Serawit Deyno analyzed and interpreted the data, and prepared the manuscript. Both authors have read and approved the final manuscript.

\section{References}

1. Weiss MG CA, Eisenberg L:: Mental health. In International public health. In. Edited by Edited by Merson MH BR, Mills AJ. Maryland: Aspen Publishers; 2001: 331-378.

2. WHO: WHO report on the global tobacco epidemic. In. Edited by Organization WH. Geneva; 2013.

3. Gillilaand FD, Islam T, Berhane K, Gauderman WJ, McConnell R, et al. (2006) Regular smoking and asthma incidence in adolescents. Am J Respir Crit Care Med 174: 1094-1100.

4. Elders MJ, Perry CL, Eriksen MP, Giovino GA (1994) The report of the Surgeon General: preventing tobacco use among young people. Am J Public Health 84: 543-547.

5. Warren CW, Jones NR, Peruga A, Chauvin J, Baptiste JP, et al. (2008) Global youth tobacco surveillance, 2000-2007. MMWR Surveill Summ 57: 1-28.

6. Nelson E (2001) The miseries of passive smoking. Hum Exp Toxicol 20: 61-83.

7. Assessment. OoEHH: Health Effects of Exposure to Environmental Tobacco Smoke. In.; 1997.

8. U.S. Department of Health and Human Services. : The Health Consequences of Involuntary Exposure to Tobacco Smoke: A Report of the Surgeon General. Atlanta:. In. Edited by Services USDoHaH: Centers for Disease Control and Prevention, National Center for Chronic Disease Prevention and Health Promotion, Office on Smoking and Health; 2014.

9. Y: K: Cigarette smoking and khat chewing among college students in North West Ethiopia. Ethiopian Journal of Health Development 2002, 16 9-17.

10. Kassaye M, Sherief HT, Fissehaye G, Teklu T (1999) Drug use among school students in Addis Ababa and Butajira. Ethiopian Journal of Health Development 13: 101-106.

11. Central Statistical Authority (2006) Ethiopia demographic and health survey. In Edited by ORC Macro Calverton, Addis Ababa, Ethiopia and Calverton, Maryland, USA.

12. Global Tobacco Surveillance System Collaborating Group (2005) Global Tobacco Surveillance System (GTSS): purpose, production, and potential. J Sch Health 75: 15-24.

13. WHO: World Health Organization global status report In. Edited by) a. Geneva; 1984
14. Ahmed Z, Abuhay M (1979) The prevalence of cigarette-smoking among secondary school children in Gondar City, Ethiopia. Ethiop Med J 17: 41-46.

15. Zein ZA, Admasu M, Tadesse M, Laeke N, Olango P, et al. (1984) Patterns of cigarette-smoking among Ethiopian medical and paramedical students. Ethiop Med J 22: 165-171.

16. Deressa W, Azazh A (2011) Substance use and its predictors among undergraduate medical students of Addis Ababa University in Ethiopia. BMC Public Health 11: 660.

17. Andargachew K, Fiker T, Awoke Y (2014) Prevalence and Factors Determining Psycho active Substance (PAS) use among Hawassa University Undergraduate Students, Hawassa, Ethiopia. Journal of BMC Public Health 2014.

18. Gebreslassie M, Feleke A, Melese T (2013) Psychoactive substances use and associated factors among Axum University students, Axum Town, North Ethiopia. BMC Public Health 13: 693.

19. WHO: Report on global tobacco epidemic. In. Edited by organization wh. Geneva 2008.

20. Reda AA, Moges A, Yazew B, Biadgilign S (2012) Determinants of cigarette smoking among school adolescents in eastern Ethiopia: a crosssectional study. Harm Reduct J 9:39.

21. Reda AA, Kotz D, Biadgilign S (2013) Adult tobacco use practice and its correlates in eastern Ethiopia: a cross-sectional study. Harm Reduct J 10: 28.

22. Kebede Y (2002) Cigarette smoking and khat chewing among university instructors in Ethiopia. East Afr Med J 79: 274-278.

23. DACA: A Report On Global Youth Tobacco Survey (GYTS) Conducted in Secondary Schools in Addis Ababa-Ethiopia. In. Edited by Ethiopia DAaCADo. AddisAbaba; 2005.

24. Centers for Disease Control and Prevention (CDC) (2010) Vital signs: nonsmokers' exposure to secondhand smoke --- United States, 1999-2008. MMWR Morb Mortal Wkly Rep 59: 1141-1146.

25. van den Bree MB, Whitmer MD, Pickworth WB (2004) Predictors of smoking development in a population-based sample of adolescents: a prospective study. J Adolesc Health 35: 172-181.

26. Azale T (2007) Assesment of prevalence and risk factor of chat chewing among in school and out school youth in Gonder town Ethiopia. In. Edited by Medicine DoC. Addis Ababa University; 2007. 